\title{
The effect of weather and its changes on emotional state - individual characteristics that make us vulnerable
}

\author{
Z. Spasova \\ National Center of Public Health and Analyses, Sofia, Bulgaria \\ Correspondence to: Z. Spasova (z_spassova@abv.bg)
}

Received: 30 December 2010 - Revised: 8 December 2011 - Accepted: 5 March 2012 - Published: 27 March 2012

\begin{abstract}
Given the proven effects of weather on the human organism, an attempt to examine its effects on a psychological and emotional level has been made. Emotions affect the bio tone, working ability, and concentration; hence their significance in various domains of economic life such as health care, education, transportation, and tourism.

The present pilot study was conducted in Sofia, Bulgaria over a period of eight months, using five psychological methods: Eysenck Personality Questionnaire, State-Trait Anxiety Inventory, Test for Self-assessment of the emotional state, Test for evaluation of moods and Test "Self-confidence-Activity-Mood". The FiodorovChubukov's complex-climatic method was used to characterize meteorological conditions in order to include a maximal number of meteorological elements in the analysis. Sixteen weather types are defined depending on the meteorological elements values according to this method. Abrupt weather changes from one day to another, defined by the same method, were also considered.

The results obtained by t-test showed that the different categories of weather led to changes in the emotional status, which indicates a character either positive or negative for the organism. The abrupt weather changes, according to expectations, have negative effects on human emotions - but only when a transition to the cloudy weather or weather type, classified as "unfavorable", has been realized. The relationship between weather and human emotions is rather complicated since it depends on individual characteristics of people. One of these individual psychological characteristics, marked by the dimension "neuroticism", has a strong effect on emotional reactions in different weather conditions. Emotionally stable individuals are more "resistant" to the weather influence on their emotions, while those who are emotionally unstable have a stronger dependence on the impacts of weather.
\end{abstract}

\section{Introduction}

The weak but significant relationship between weather and mood is one of the oldest and most frequent topics in popular biometeorology. Although the statement seems intuitively obvious, the experimental verification of this relationship has been difficult and complex (Persinger, 1975). Studies on the effect of weather on human emotions are relatively low in number and in Bulgaria they are an exception. These studies are also difficult to interpret, susceptible of confounding variables, and of mixed results (Scott, 2007). Most of them focus on the relationship between the weather and mood.
Barnston (1988) performed an experiment in which 62 university student subjects in Illinois kept structured diaries of their feelings and their productivity for six weeks in early autumn. During the same period, he monitored the daily frequency of telephone calls to a crisis intervention service and collected the complete daily weather data for the vicinity from a local meteorological research facility. The results show that the weather appears to influence mood and productivity, but only to a small extent compared with the aggregate of all other controlling factors. Males experienced a relatively stronger effect than females. Psychologically troubled people generally appeared to be more affected by weather. People with mild problems tended to be stressed more when 
the weather is unstable, cloudy, warm and humid; and least stressed during sunny, dry, cool weather with rising barometric pressure. The crisis service clients with severe problems reacted oppositely to these two weather types.

Hribersek et al. (1987) researched 21-months of the calls to a telephone counseling service at Louvain. Contrary to Barnston (1988) they found that women are more sensitive to weather compared to men, which they explained with hormonal differences. They also explained the phenomenon women make more calls when the weather is adverse with the fact they prefer to stay at home during severe weather. This statement is supported by Trenkle (1982) and Michael and Zumpe (1983) as well.

Persinger (1975) did a detailed study on the relationship between the weather and mood. He calculated correlations between daily self-evaluated mood reports (4 reports/day) of 10 student subjects and 10 meteorological-geophysical variables over a 90-day period. The variables are mean and/or change measures of temperature, barometric pressure, relative humidity, sunshine hours, wind speeds and global geomagnetic activity. Multiple regression analyses indicate that the weather matrix used could account for not more than $35 \%$ of the mood variance on the day of the evaluation. Lag correlations over the previous week indicates a greater number of significant correlations between mood reports and weather of the previous two days. The mean correlation coefficient is 0.27 . The author concluded that "lower moods" are associated with fewer sunshine hours, higher relative humidity, and smaller humidity variations than "higher moods". It is concluded that mood reports can show weak response to antecedent weather fluctuation.

Howarth and Hoffman (1984) investigated the relationship between eight weather variables (hours of sunshine, precipitation, temperature, wind direction, wind velocity, humidity, change in barometric pressure and absolute barometric pressure) and 10 mood variables (concentration, cooperation, anxiety, potency, aggression, depression, sleepiness, skepticism, control, and optimism). Data was collected from 24 male subjects over 11 consecutive days. The results show that "humidity, temperature and hours of sunshine have the greatest effect on mood. High levels of humidity lowered scores on concentration, while increasing reports of sleepiness. Rising temperatures lowered anxiety and skepticism mood scores".

Palinkas (2001) compared cold temperatures with mental processes. He found that low temperatures influence the concentration of attention, memory and general cognitive processes. "There is evidence of a dose-response relation involving decrements in cognitive performance with respect to decline in core body temperature and complexity of tasks performed. However, it is unclear whether these effects are due to distraction or increased anxiety."

Mood disturbances like nervousness, irritability, aggressiveness or phlegm, reduced concentration of attention are symptoms of so-called foehn illness. As many authors say, these symptoms could be registered during extreme temperature changes and during the passage of weather fronts (Tromp, 1979; Fletcher, 1988); rapid drop of atmospheric pressure followed by its rapid rise (Fletcher, 1988); strong winds blowing (Auliciems, 1978; Thomson, 1979; Sulman, 1980; Fletcher, 1988).

Some of the authors make attempts to connect the perception of weather with the residence of investigated people and with their personal characteristics. Scott (2007) hypothesize the "relocated individuals are more susceptible to fluctuations in mood stemming from novel weather conditions than indigenous individuals". He has conducted a research with 70 life-long Minnesota residents and 25 individuals who have spent minimum of one year living outside of Minnesota. Participants completed a mood self-report measure online for four consecutive weeks to determine positive and negative affect levels. Data was then matched with corresponding weather data for the same time period. The author found no support for the hypothesis; however, "sunshine was identified as the crucial factor for mood adjustment".

Denissen et al. (2008) suggest that the individual differences may have an effect on how people perceive the weather. They press on fact that differences in sensitivity to daily weather have not been studied previously, but some studies suggest a link between seasonality and personality, especially concerning the trait of neuroticism (e.g. Jang et al., 1997; Murray et al., 1995) (cit. by Denissen et al., 2008). They use the Big Five Inventory Test (BFI) to determine if the weather influences in a different way people with different personality traits. The test is measuring Extraversion, Neuroticism, Openness to Experiences, Conscientiousness, and Agreeableness. The authors examine the effects of six weather parameters (temperature, wind power, sunlight, precipitation, air pressure, and photoperiod) on mood (positive affect, negative affect, and tiredness). They analyze the results from an online diary study of 1233 people. They reveal main effects of temperature, wind power, and sunlight on negative affect. Sunlight has a main effect on tiredness and mediated the effects of precipitation and air pressure on tiredness. According to Denissen et al. (2008) the average effect of weather on mood is small, though there is significant random variation across individuals, especially regarding the effect of photoperiod. There are also no evidences that the individual differences in weather sensitivity could be explained by the Five Factor Model personality traits, gender, or age.

Several findings in general deny the relationship between weather and emotional state in spite of finding some significant coefficients. Findikyan and Sells (1964) for example investigated students from Texas, who had to fill out a diary with their everyday subjective feelings. The group as a whole did not show significant correlations between the weather parameters and mood, although the female group showed a significant negative correlation between the dimension "humidity" and positive mood. 
Table 1. Distribution of the investigated persons by sex and age (\%).

\begin{tabular}{lcccccc}
\hline Sex & \multicolumn{5}{c}{ Age groups } & Mean age \\
\cline { 2 - 6 } & $16-20$ & $21-30$ & $31-40$ & $41-50$ & $51-60$ & \\
\hline Males (44) & 25 & 4 & 5 & 7 & 3 & 23.48 \\
Females (143) & 90 & 17 & 13 & 17 & 6 & 26.36 \\
\hline All (187) & 115 & 21 & 18 & 24 & 9 & 25.68 \\
\hline
\end{tabular}

Watson's (2000) research is of diary reports of eight different samples of students from Texas (total number of 478 people) for 8-yr period - 1985-1993. Analyzing the amount of sunshine and rain, he fails to find consistent effect on any of the daily mood variables. Interested if the extreme weather conditions have an effect on people's mood, Watson (2000) also compares days with $0 \%$ sunshine with days with $100 \%$ sunshine. He finds that the sunshine only influenced the overall intensity of participants' mood reports, not the valence of these reports.

Driscoll and Stillman (2002) analyzed the calls to telephone counseling services ("hotlines") each serving communities in a major metropolitan area of the United States (Detroit, Washington DC, Dallas and Seattle) for the period 1997-1998. They investigated associations with subjectively derived weather types for all cities except Seattle, as well as with individual weather elements as cloudiness, precipitation, wind speed, and interdiurnal temperature change for all four cities. The authors reveal that despite the statistically significant results "obtained in scattered instances, the total number was within that expected by chance", and that "there was little in the way of consistency with these associations". One exception is the increase of call frequency during severe weather, "when there is obvious concern about the damage done by it".

Keller et al. (2005) investigate the effect of temperature and barometric pressure on mood and cognition (memory and cognitive style) of 97 North American participants. The authors do not find consistent main effect of weather on mood, though they observe that pleasant weather (with higher temperature or barometric pressure) is "related to higher mood, better memory and "broadened" cognitive style during the spring" (only this season) "as time spent outside increased". On hot summer days, conversely, spending more time outside is associated with deteriorated mood. "These results are consistent with findings on seasonal affective disorder, and suggest that pleasant weather improves mood and broadens cognition in spring because people have been deprived of such weather during the winter".

The contradictions in the results of the listed studies reveal that the issue requires an additional consideration. We hope our study, in spite being a pilot limited in time, would contribute in revealing some aspects of the weather's influence on human emotional state.

\section{Data and methods}

The present research took place in Sofia City during 25 days within a period of 8 months (November 1998-June 1999). A group of 187 volunteers was examined. Their number varied for different dates. The group included males and females aged between 16 and $60 \mathrm{yr}$, without serious disturbances in their physical and mental status. Among the persons examined, there were secondary and high school students, teachers and university lecturers, workers and pensioners. Detailed information about the gender and age distribution of the tested people is given in Table 1 .

Five psychological methods were used - four of them intended for emotional state analysis, while the fifth determined the human temperament.

One of the most frequently used questionnaires for assessing anxiety as an emotional state is the State-Trait Anxiety Inventory (STAI) (Spielberger et al., 1970). The test has been adopted for Bulgarian population by Shtetinski and Paspalanov (1989). STAI is a self-evaluating test, which comprises of two separate scales, which measure the S-anxiety (Y-1 form) and T-anxiety (Y-2 form). In the S-scale, the main qualities being under scrutiny are related to the socalled "gloomy presentiment" (i.e. the sensation of danger) of the tension, nervousness and inconvenience type. This scale measures the situative anxiety. In the T-scale, the assessed qualities are related to the persistent sensation of danger, tension and nervousness (i.e. it includes the extent of proneness to anxiety). The evaluation of the test results is done individually for each researched individual following the key to the STAI test. The numerical values obtained for all items on each scale are collected and the result is compared with test norms for the scale. The marks on both scales can vary in the range between 20 and 80 points.

The Test for Self-assessment of the emotional state (SAES) was developed by the American psychologists A. Wessman and D. Ricks. It is comprised of four subscales: "calmness-anxiety", "vigor-tiredness", "high spiritslow spirits" and "self-confidence - lack of self-confidence" (Karelin, 1997).

The test "Evaluation of moods" investigates the most prolonged emotional state, which determines one's attitude toward the environment (Karelin, 1997). The test diagnoses three states of the mood: normal, euphoric mood, and 
asthenic state (it shows the negative moods of the subjects at the moment of taking the test).

The "Self-confidence-Activity-Mood" (SCAM) Questionnaire was developed by specialists from the Military Academy in Saint Petersburg, and is designed for operational evaluation of self-confidence, activity and mood of subjects (Rimskii and Rimskii, 1995).

The Eysenck Personality Questionnaire (EPQ) (Paspalanov et al., 1984) does not measure the emotional state of the subjects. It was included in the study because it is the one which has a scale of "lie", serving as an indicator of the reliability of responses. That also makes it possible to recognize the impact of weather on people having major basic personality traits such as extraversion, psychoticism, and especially neuroticism which is directly connected with human emotional states and processes.

Neuroticism and emotional stability are basic personal characteristics that refer to emotionality as a personality trait. On physiological level they are connected with the inflammability level of the autonomic nervous system and visceral brain. Individuals who score high on neuroticism are more likely than the average to experience feelings as anxiety, guilt, anger, and depressed mood (Matthews and Deary, 1998). They respond more poorly to environmental stress, they are often self-conscious and shy, and they may have trouble controlling urges and delaying gratification (Goleman, 1997). They are highly emotional and impressionable, with strong reactions to the all kind of stimulus and return slower to the normal state. Emotionally stable individuals have higher thresholds of emotional reaction, they return faster to the normal state after emotionally excitement. They are usually calm, steady, and control themselves well. They have higher adaptive abilities especially in stressful situations (Eysenck and Eysenck, 1975).

The Fiodorov-Chubukov's complex-climatic method (see Tishkov, 1985) was used to characterize meteorological conditions for the purpose of including in the analysis a maximal number of meteorological elements. The method considers cloudiness ass well, an important factor for purposes of our study as it has been found the sunlight has a significant effect on mood. Lambert et al. (2002) states that "the rate of production of serotonin by the brain was directly related to the prevailing duration of bright sunlight and rose rapidly with increased luminosity". Another advantage of the complexclimatic method is that it has been applied for characterizing the climate of Sofia which makes the results of our study applicable.

According to Fiodorov-Chubukov's complex-climatic method there are three major types of weather: warm weather, weather with transition of temperature through $0{ }^{\circ} \mathrm{C}$, and frosty weather. These weather groups include 16 weather types/classes (see Figs. 1 and 2).

Abrupt weather changes from one day to another, defined by the same method (Fig. 3) were considered as well, with the presumption they could be a source of additional environmental stress on the tested people.

Y. Ajizkii (cited by Boksha and Bogutskii, 1980) classified the 16 weather types according their impact on human biocomfort. He differentiated three groups:

1. Favorable weather types (II, III, IV, V, IX, X, XI types);

2. Relatively favorable weather types (I, VI, VIII, XII);

3. Unfavorable weather types (VII, XVI, XIII, XVI and $\mathrm{XV}$ ), as well as weather types from the second group with strong wind blowing (over $9 \mathrm{~m} \mathrm{~s}^{-1}$ ), storm, fog, hailstorm, blizzard, or sand storm.

By recurrence of testing in the same weather types with the same persons, we managed to eliminate the suspicion that it was weather that leads to certain emotional states. We also conducted a brief inquiry which helped us to eliminate responses of those people whose emotions at the time of survey were strongly influenced by external factors. The statistical processing of the results included calculation of the average values and standard deviation for grouped data and comparative analysis through the $\mathrm{t}$-test.

\section{Hypotheses of the study}

\subsection{First hypothesis}

It can be assumed that different weather classes will affect the emotional state of people and that influence will show statistically significant differences among the different weather groups (favorable, relative favorable and unfavorable).

\subsection{Second hypothesis}

It is expected that abrupt weather changes will provoke negative emotions in subjects.

\subsection{Third hypothesis}

It is believed that changes in emotional state affected by weather will depend on individual differences of people; they will be stronger in people with high levels of neuroticism.

\section{Results and discussion}

During the 25 days of testing, seven of the 16 weather types were observed - both sunny and cloudy in some of the types from the groups, with transition of temperature through $0^{\circ} \mathrm{C}$ and frosty weather. The following weather types have been observed: III (slightly cloudy) - in 7 days; VII (rainy) - in 1 day, VIII (weather with transition of the temperature through $0{ }^{\circ} \mathrm{C}$ - warm spell) - in 4 days, IX (weather with transition of the temperature through $0{ }^{\circ} \mathrm{C}-$ cold spell) -6 days, $\mathrm{X}$ (slightly frosty) -2 days, XI (moderate frosty) -4 days and 


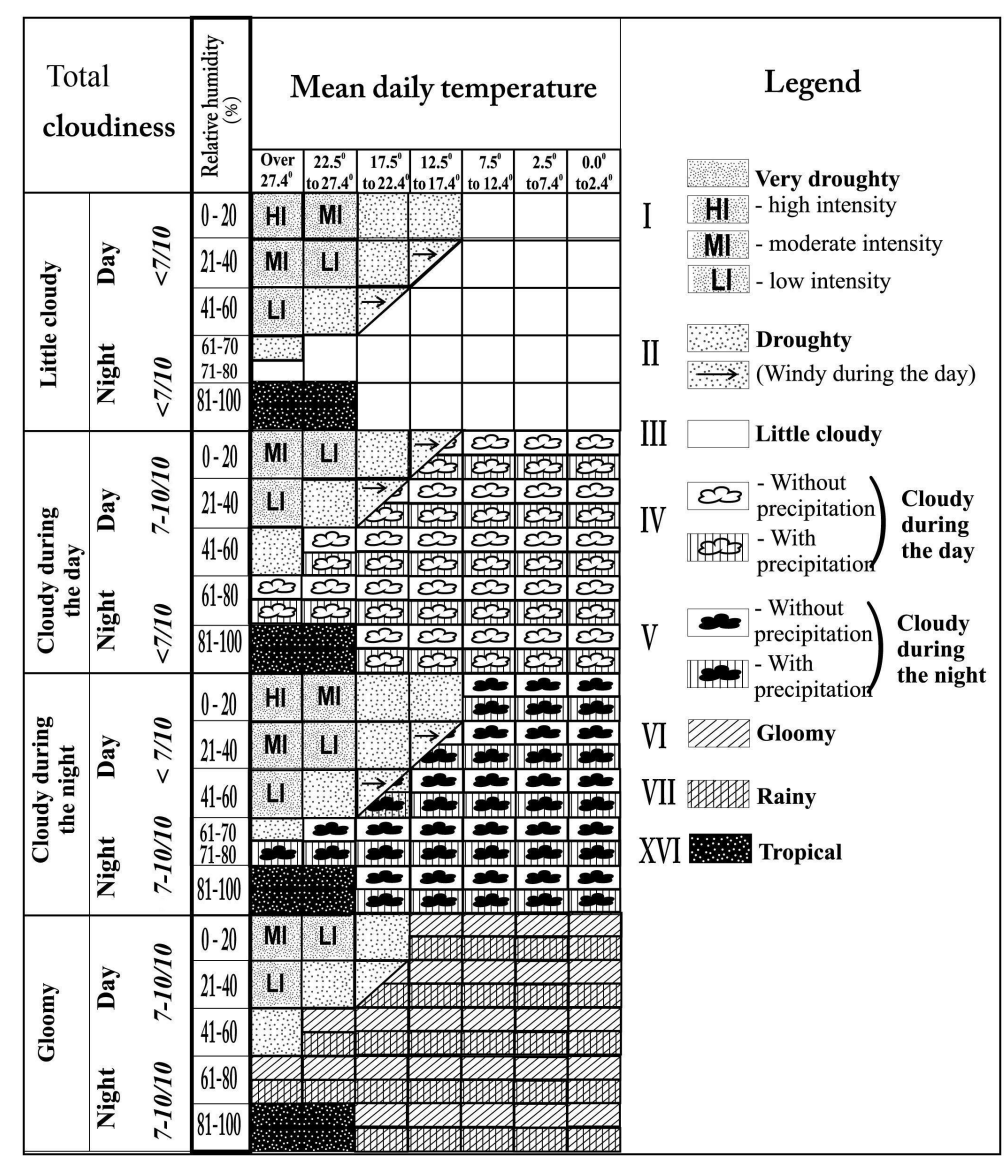

Figure 1. Weather classes during the warm part of the year (source: Tishkov, 1985).

\begin{tabular}{|c|c|c|c|c|c|c|c|}
\hline $\begin{array}{l}\text { № of weather } \\
\text { classes }\end{array}$ & VIII & $I X$ & $x$ & $X I$ & $X I I$ & XIII & $X I V$ \\
\hline \multirow{2}{*}{$\begin{array}{l}\text { Names of } \\
\text { the weather } \\
\text { classes }\end{array}$} & \multicolumn{2}{|c|}{$\begin{array}{l}\text { Weather with transition } \\
\text { of temperature } \\
\text { through } 0^{\circ} \mathrm{C}\end{array}$} & \multirow{2}{*}{$\begin{array}{l}\text { Slightly } \\
\text { frosty }\end{array}$} & \multirow{2}{*}{$\begin{array}{c}\text { Moderate } \\
\text { frosty }\end{array}$} & \multirow{2}{*}{$\begin{array}{c}\text { Consi- } \\
\text { derable } \\
\text { frosty }\end{array}$} & \multirow{2}{*}{$\begin{array}{c}\text { Strongly } \\
\text { frosty }\end{array}$} & \multirow{2}{*}{$\begin{array}{l}\text { Hardly } \\
\text { frosty }\end{array}$} \\
\hline & Warm spell & Cold spell & & & & & \\
\hline $\begin{array}{c}\text { Average diurnal } \\
\text { temperature }\end{array}$ & - & + & $0.0^{\circ}$ t $0-2.4^{\prime}$ & $-2.5^{\circ}$ to $-7.4^{4}$ & $-7.5^{\circ}$ to $-12.4^{\circ}$ & $-12.5^{\circ}$ to -17.4 & under -17.4 \\
\hline$T \max$ & + & + & \multicolumn{4}{|c|}{ Below zero } & \\
\hline $\mathrm{T}$ min & - & - & \multicolumn{4}{|c|}{ Below zero } & \\
\hline Calm & & & & & & & \\
\hline Windy & 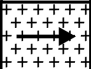 & & & & IIII & z & $\frac{1}{15}$ \\
\hline
\end{tabular}

Figure 2. Weather classes during the cold part of the year (source: Tishkov, 1985).

XVI (tropical) - 1 day. Here we provide a short description of the observed weather types during the study period:

Class III (partly cloudy) is characterized with cloud cover less than 7/10 during the day and night. Temperature and humidity may vary broadly, but usually the class is characterized with moderate values of these meteorological elements.
Class VIII (rainy) is observed when cloud cover is more than $7 / 10$ during the day and night, with precipitation of rain. In most cases this weather type is connected with atmospheric frontal passage. "Such type of weather often provoke depressive mood in people." (Hristov and Tanev, 1978).

Class VIII and class IX (weather with transition of temperature through $0{ }^{\circ} \mathrm{C}$ ) is characterized by temperatures above and below $0{ }^{\circ} \mathrm{C}$ - during class VIII the maximum temperature is above $0{ }^{\circ} \mathrm{C}$, while the minimum and diurnal average temperatures are below $0{ }^{\circ} \mathrm{C}$; and during class IX the maximum and diurnal mean temperatures are above $0^{\circ} \mathrm{C}$, while the minimum temperature is negative.

Frosty weather is characterized by negative mean, maximum and minimum temperatures and is divided accordingly its severity in five classes (see Fig. 2).

On four of the days of the study period abrupt changes of weather occurred (see Table 2).

\subsection{Results of the first hypothesis}

The results of all tests and their sub-scales showed an increase of negative emotions during adverse weather type occurrences - although in the group of favorable weather types 


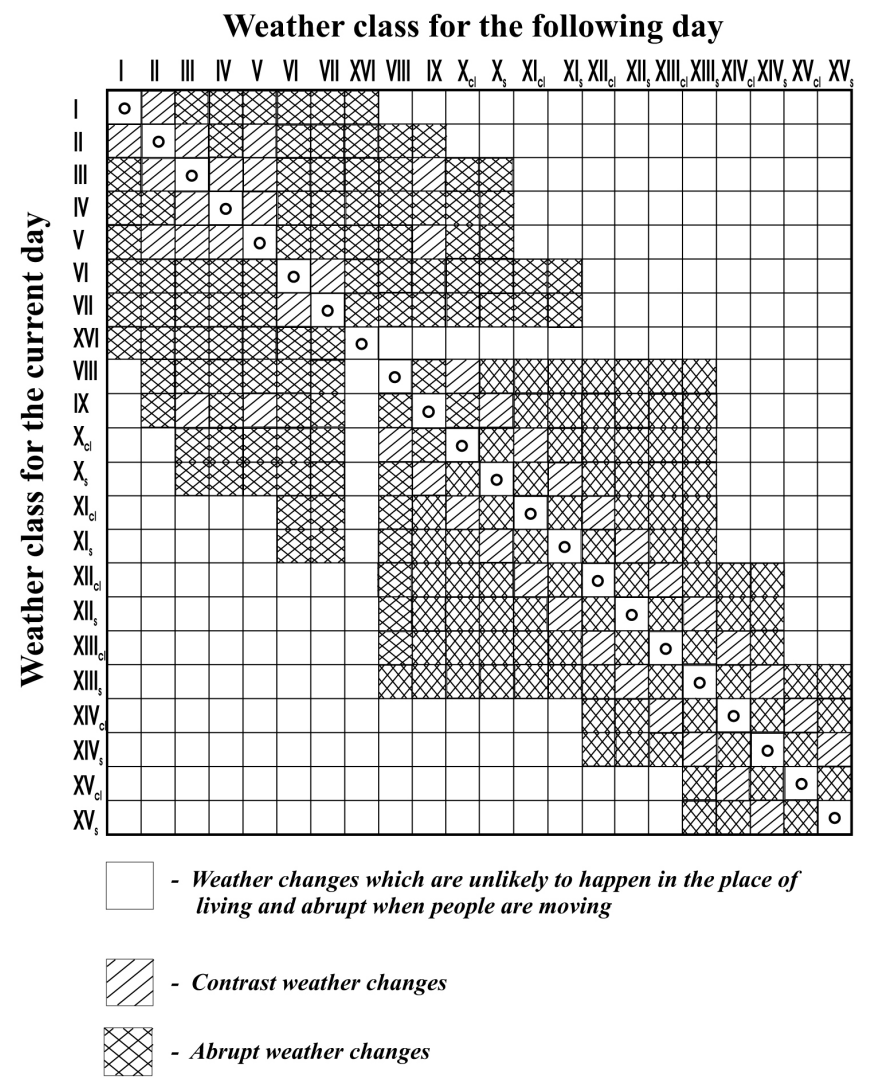

Figure 3. Scheme for determination the contradistinction of the weather changes (source: Baibakova et al., 1966).

there were contradictory results. It should be concluded that weather types defined as "favorable" do not always have a favorable effect on human emotions. For example, we had investigated weather types VII (rainy) and XVI (tropical) from the group of unfavorable weather classes with tests STAI and SAES. The statistical relation of class XVI (tropical) and classes III (little cloudy), VIII (with transition of temperature through $0{ }^{\circ} \mathrm{C}$ - warm spell), IX (with transition of temperature through $0{ }^{\circ} \mathrm{C}$ - cold spell) and $\mathrm{X}$ (slightly frosty) revealed that there are significant differences only with III and IX weather type. This can be interpreted as low favorability of classes VIII and X in terms of emotions, and higher for classes III and IX. This finding is confirmed by the relationship between the above mentioned four classes. In all methods used in almost all cases (except two) between class III and IX, on the one hand, and class VIII and X, on the other, significant differences are realized. Mean average values in different sub-scales showed that the first couple of weather types have a positive impact on human emotions and the second pair - a negative impact.

Significant differences have been observed between IX (weather with transition of temperature through $0^{\circ} \mathrm{C}-$ cold spell) and III (little cloudy) types at the one hand, and type XI (moderate frosty) on the other. The latter also belongs to the group of favorable classes. These differences and the mean average values of the test SCAM showed that the XI type (moderate frosty) has less beneficial effect on human emotional processes and states compared with III and IX classes, although it is also a part of the favorable group.

\subsection{Results of the second hypothesis}

As we mentioned above, during the period of the research abrupt weather changes on four days were observed. In two of the cases a favorable weather class is changed with another favorable weather class (X cloudy turns to IX and IX turns to XI cloudy). One of the abrupt weather changes is when weather turns from unfavorable to favorable class (class VII has been changed with class IX). We have also observed one transition from favorable weather class to unfavorable weather class (when type IX has been changed with VII) (see Table 2).

The results of the hypothesis show that we could speak of a tendency of negativity of emotional states during abrupt weather changes, but not for objective law. Moreover, the presence of normal emotional state indicates that abrupt changes do not have a consistent influence on the human emotional state - but are internally differentiated. Probably there are transitions from one weather class to another which alter the effects of contrasting weather changes depending on the direction of the occurring transitions.

This is confirmed by analysis of weather changes during the dates of the study. Normal emotional state is observed when the weather is changing to classes from the "favorable" group, or when weather turns from cloudy to sunny. In cases of transition from favorable weather class to unfavorable weather class we observe negative emotional state, in our case - heightened anxiety (see Table 2).

\subsection{Results of the third hypothesis}

The all 187 persons involved in the study have been tested once with EPQ. Women prevail forming about $3 / 4$ of the group (see Table 1). The share of neurotic people is $58.3 \%$ and emotionally stable are $35.8 \%$ (Fig. 4). The mean value of neuroticism scores is 13.06 for the group.

In our third hypothesis we expected that people with higher neuroticism scores would be more affected by the weather and its changes. The results entirely confirmed our assumption. We had investigated the relationship between emotionally stable people and neurotic people (ambiverts, the individuals characterized with the same degree of emotional stability and neuroticism had been excluded from the analysis). The obtained values by t-test are high - not only in its statistical significance, but also as a numerical score.

The biggest differences in the sub-scale for high mood are observed in the SAES test (Table 3). Obviously the greater sensitivity of the neurotics affects their emotional reaction to changes in environment, including weather changes. As a 
Table 2. Qualitative assessment of the emotions of the volunteers by mean average values in different sub-scales during abrupt weather changes.

\begin{tabular}{|c|c|c|c|c|}
\hline \multirow[t]{2}{*}{ Abrupt weather changes } & \multicolumn{4}{|c|}{ SAES Test } \\
\hline & I & II & III & IV \\
\hline $\mathrm{Xcl} \rightarrow \mathrm{IXs}$ & 4.40 & 4.70 & 4.36 & 4.80 \\
\hline $\begin{array}{l}\text { /Slightly frosty (cloudy) } \rightarrow \text { Weather with transition } \\
\text { of temperature through } 0{ }^{\circ} \mathrm{C}-\text { cold spell (sunny)/ }\end{array}$ & \multicolumn{4}{|c|}{$\begin{array}{l}\text { Moderately negative, } \\
\text { close to normal state }\end{array}$} \\
\hline $\mathrm{VII} \rightarrow \mathrm{IXcl}$ & 5.33 & 5.63 & 5.72 & 5.81 \\
\hline \multirow[t]{2}{*}{$\begin{array}{l}\text { /Rainy } \rightarrow \text { Weather with transition of } \\
\text { temperature through } 0{ }^{\circ} \mathrm{C}-\text { cold spell (cloudy)/ }\end{array}$} & \multicolumn{2}{|l|}{$\begin{array}{l}\text { Moderately } \\
\text { negative }\end{array}$} & \multicolumn{2}{|c|}{$\begin{array}{l}\text { Normal } \\
\text { emotional state }\end{array}$} \\
\hline & \multicolumn{4}{|c|}{ Test Evaluation of Moods } \\
\hline $\mathrm{IXs} \rightarrow \mathrm{XIcl}$ & I & II & & III \\
\hline \multirow{2}{*}{$\begin{array}{l}\text { /Weather with transition of temperature through } 0{ }^{\circ} \mathrm{C} \\
\text { - cold spell (sunny) } \rightarrow \text { Moderate frosty (cloudy)/ }\end{array}$} & 4.03 & 4.50 & & 4.91 \\
\hline & Moderately & egative & & $\begin{array}{l}\text { Normal } \\
\text { emotional } \\
\text { state }\end{array}$ \\
\hline $\mathrm{IXcl} \rightarrow \mathrm{VII}$ & \multicolumn{4}{|c|}{ STAI Test - S-anxiety } \\
\hline $\begin{array}{l}\text { /Weather with transition of temperature through } 0{ }^{\circ} \mathrm{C} \\
\text { - cold spell (cloudy) } \rightarrow \text { Rainy/ }\end{array}$ & \multicolumn{4}{|c|}{44.18 - Heightened anxiety } \\
\hline
\end{tabular}

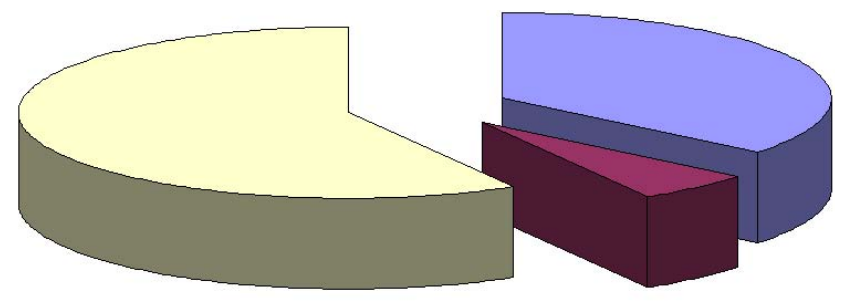

Emotionally stable $\quad \square$ Ambiverts $\quad \square$ Neurotic people

Figure 4. Distribution of the investigated people according to dimention Neuroticism/Stability.

matter of principle, the same thing is observed for the other three sub-scales - which measure other kinds of emotional states. Results on these sub-scales are lower but remain statistically significant. In smallest (but statistically significant) degree, weather affects self-confidence of people with different emotional stability. The reasons for this have already been discussed.

The results of the test "Evaluation of moods" show some specifics of meaningful and quantitative nature. The values of sub-scales which measure mood and asthenic state are not only significant, but also high; while the euphoria result is statistically insignificant. This test shows that the individual differences in neuroticism dimension affects strongly the mood - and in lesser extent - the asthenic state of people. Euphoria does not show significant changes in this comparison as well (Table 3).

The results of SCAM test show that all t-test values are statistically significant, but it is interesting that the highest value is of the sub-scale measuring self-confidence, followed by those measuring mood and activity (Table 3 ). It seems that one of the peculiarities of neurotics lies in the fact that the increased excitability of their nervous system has a strong impact of their self-feeling. Probably this reflects on their entire perception of the world and strongly affects their selfconfidence. Different number of tested people on both tests (SCAM and SAES) could also change the ratio. In the same direction works the different weather types during the testing procedure of both groups. Finally, another important fact is that the SCAM test has a slightly higher level of reliability of the results, which inevitably has given its impact on the ratio of results obtained by the different sub-scales.

The results of STAI test showed significant differences between neurotics and emotionally stable people, although they are minimal $\left(\mathrm{t}_{\text {critical }}=1.98\right)$ (see Table 3$)$. STAI has a maximum level of reliability, which makes its results highly accurate. Moreover it measures only S-anxiety while the SAES test does not differentiate the personal and situational anxiety. This is the main reason for the quantitative differences in measurement of anxiety between these tests, and which did not affect the quality of the value of benchmarking which remains significant in both cases. 
Table 3. Comparative analysis by t-quotient of the results of the used psychological methods for the impact of the weather on people with different neuroticism scores.

\begin{tabular}{|c|c|c|c|c|}
\hline \multicolumn{5}{|c|}{ SAES Test } \\
\hline Sub-scales & Calmness & Energy & High mood & Self-confidence \\
\hline \multirow[b]{2}{*}{$\mathrm{N}$ (neurotic people) - 135 persons } & $\mathrm{S}$ (stable) - 93 persons & $\mathrm{S}$ & $\mathrm{S}$ & $\mathrm{S}$ \\
\hline & $4.07^{*}$ & $3.71^{*}$ & $4.52^{*}$ & $3.53^{*}$ \\
\hline \multicolumn{5}{|c|}{ Test Evaluation of Moods } \\
\hline Sub-scales & Mood & Asthenic state & \multicolumn{2}{|l|}{ Euphoria } \\
\hline \multirow{2}{*}{$\mathrm{N}-92$ persons } & $\mathrm{S}-71$ persons & $\mathrm{S}$ & \multirow{2}{*}{\multicolumn{2}{|c|}{$\begin{array}{l}\mathrm{S} \\
1.23\end{array}$}} \\
\hline & $5.90^{*}$ & $4.57^{*}$ & & \\
\hline \multicolumn{5}{|c|}{ SCAM Test } \\
\hline \multirow[t]{2}{*}{ Sub-scales } & Self-confidence & Activity & \multicolumn{2}{|l|}{ Mood } \\
\hline & $S-69$ persons & $\mathrm{S}$ & \multirow{2}{*}{\multicolumn{2}{|c|}{$\begin{array}{l}\mathrm{S} \\
2.97^{*}\end{array}$}} \\
\hline \multirow[t]{2}{*}{$\mathrm{N}-95$ persons } & $4.57^{*}$ & $2.94^{*}$ & & \\
\hline & \multicolumn{4}{|l|}{ STAI Test } \\
\hline \multirow{2}{*}{\multicolumn{2}{|c|}{$\begin{array}{c}\text { S-anxiety } \\
\mathrm{N}-109 \text { persons }\end{array}$}} & & \multirow{2}{*}{\multicolumn{2}{|c|}{$\begin{array}{c}\mathrm{S}-67 \text { persons } \\
1.99^{*}\end{array}$}} \\
\hline & & & & \\
\hline
\end{tabular}

${ }^{*}$ The quotients marked with an asterisk are statistically significant.

\section{Discussion}

The aim of our research was to reveal the effect of different weather types and abrupt weather changes on people's emotions and to find if there are differences in perception of weather for people with different neuroticism scores.

As a pilot study the present research had some limitations that should be discussed. It did not include the effect of the whole number of 16 weather types of the used classification for several reasons. Despite the limited number of dates of testing, the described weather types have also a different frequency during the year. Some of their manifestations are exceptional for the climate of Sofia, like XVI (tropical), XIV (hardly frosty) and XV class (severe frosty). The XV class has been even excluded from the adjusted classification for Bulgaria because it's not typical for the country. At the same time, weather class number III (little cloudy) is observed during all months of the year, varying from $1 \%$ of the days in January to almost half of the days in September (46\%). The same is valid for rainy weather (class VII) which is observed throughout the year, ranging from $3 \%$ in January and February to almost a quarter of the days in April, May and June. Weather with transition of temperature trough $0{ }^{\circ} \mathrm{C}$ (VIII and IX class) is typical for the spring and autumn but is often observed during the winter as well (Hristov and Tanev, 1978). This fact requires more precise choosing of the dates of testing people in which the weather forecast could play an important role. As we found some contradictions in terms of favourableness of the weather types given by Ajizkii, the re- sults of a more detailed study could be used for determination the effect of weather types on human emotions and even classifying the weather in a new way accordingly its positive or negative effect on the emotional state.

Another problem we strike concerned testing of people with different psychological methods. It has been found that if a particular group is tested frequently with the same tests that might lead to inaccurate results because many people will give similar answers. That requires testing a bigger number of people for a longer period.

Even describing the effect of a limited number of weather types on human emotions we could notice that the negative effect of the unfavorable weather classes is clearly manifested. This result confirmed the findings of Denissen et al. (2008) who state that the weather considerably affects negative emotions measured by items "afraid", "scared", "nervous", "jittery", irritable", "hostile", "guilty", "ashamed", "upset", and "distressed". Our findings although state the weather can affect in a different extend the positive emotions as well. Actually we found that all of the emotional states excluding euphoria are affected by the weather. It is understandable because euphoria is an extreme emotion influenced by very strong positive factors for the person. The rest of emotional states are affected in different extend by the weather. The strongest is the effect of the weather on mood, which varies widely according to the weather characteristics. To a smaller extent, weather affects activity, asthenic state, vigor, anxiety and high mood. Self-confidence is lesser influenced by weather, which could be considered normal because 
it depends mostly on individual experience, way of life, social status, education, etc. It could be concluded from the present study that weather influences the simple and shortlived emotional states, while in the complicated and longlived emotions its effect is lower or non-existent.

We also supposed that the abrupt weather change is a stressor for the human organism and therefore should negatively affect people's physiological and respectively emotional state. This assumption although was not fully confirmed by the results of the study (see Sect. 4.2). One of the possible explanations could be the age of the tested volunteers. They were young and they may have higher potential to adapt to changing weather; while for older people, especially those with chronic diseases, this would require physiological tension which could lead to negative emotions. Another explanation is the character of abrupt weather changes, as when the weather "improves" (turns from unfavorable to favorable types or from cloudy to sunny) the emotional state improves as well. The problem requires drawing a deeper attention on it in the future as the abrupt weather changes are expected to increase in frequency with climate change.

We also found that the perception of weather and its changes strongly depends on individual psychological characteristics of people. Our assumption does not confirm the findings of Denissen et al. (2008) who were not able to prove that the individual differences in weather sensitivity could be explained by the Five Factor Model personality traits (one of its sub-scales is measuring neuroticism), gender, or age. Our findings reveal that neurotic people have higher sensitivity to the weather while the emotionally stable individuals are more "protected" against the weather influence on their emotions. Although not dividing the studied group by gender we could in indirect way state that women are more vulnerable to the weather because they have higher scores of neuroticism. The norms of the dimension neuroticism are 9.69 points for men and 13.25 for women (statistically significant difference). The mean value of neuroticism scores is 13.06 for the group investigated by us which could be explained by the higher percent of women.

In conclusion, we would like to emphasize that the thesis of this work deserves further development, since its theoretical and applied effects are not negligible. Emotions affect the bio tone, working ability and concentration; hence their significance in various domains of economic life, such as health care, education, transportation, and tourism. We believe the relation between climatology and psychology has a future in theoretical and practical aspects, revealing interesting dependences between climatic phenomena and psychical reactions of humans.

Acknowledgements. The author would like to thank psychologist Petar Zahariev for providing methodological help for this paper.

Edited by: T. Cegnar

Reviewed by: K. Zaninovic and three other anonymous referees

\section{sc nat \\ The publication of this article is sponsored by the Swiss Academy of Sciences.}

\section{References}

Auliciems, A.: Mood dependency on low intensity atmospheric variability, Int. J. Biometeorol., 22, 20-32, 1978.

Baibakova, E., Butyeva, I., Ilyicheva, E., and Nevraev, G.: Weather change and its assessment for the medical characterization of climate. Issues of culturology, physiotherapy and medical physical exercise, 145-150, 1966.

Barnston, A.: The effect of weather on mood, productivity, and frequency of emotional crisis in a temperate continental climate, Int. J. Biometeorol., 32, 134-143, 1988.

Boksha, V. and Bogutskii, B.: Medical climatology and climatotherapy, 1980 (in Russian).

Denissen, J., Butalid, L., Penke, L., and van Aken, M.: The effects of weather on daily mood: A multilevel approach, Emotion, 8, 662-667, 2008.

Driscoll, D. and Stillman, D.: Weather and emotional state: a search for associations between weather and calls to telephone counseling services, Int. J. Biometeorol., 47, 21-34, 2002.

Eysenck, H. and Eysenck, S.: Manual of the Eysenck Personality Questionnaire (Junior and Adult), Hodder and Stoughton, 1975.

Findikyan, N. and Sells, S.: Some relations of meteorological variables to day-to-day fluctuations in subjective feeling, in: Dimensions of stimulus situations which account for behavior variance, Contract Nour-3436(00), Group Psychology Bronch, Office of Naval Research, Research Note No. 1, 1964.

Fletcher, R.: "Föhn illness" and human biometeorology in the Chinook area of Canada, Int J Biometeorol, 32, 168-175, 1988.

Goleman, D.: Emotional Intelligence, New York, Bantam, 1997.

Howarth, E. and Hoffman M.: A multidimensional approach to the relationship between mood and weather, Brit. J. Psychol., 75, 15-23, 1984.

Hribersek, E., Van de Voorde, H., Poppe, H., and Casselman, J.: Influence of the day of the week and the weather on people using a telephone support system, Brit. J. Psychiat., 150, 189-192, 1987.

Hristov, P. and Tanev, A.: Climate of Sofia, Sofia, 1978.

Jang, K., Lam, R., Livesley, W., and Vernon, P.: The relationship between seasonal mood change and personality: More apparent then real?, Acta Psychiat. Scand., 95, 539-543, 1997.

Karelin, A. (Ed.): Encyclopaedia of psychological tests. Personality, motivation, necessities, Moscow, 1997 (in Russian).

Keller, M., Fredrickson, B., Ybarra, O., Cote, S., Johnson, K., Mikels, J., Conway, A., and Wagner, T.: A warm heart and a clear head: The contingent effects of weather on mood and cognition, Psychol. Sci., 16, 724-731, 2005.

Lambert, G., Reid. C., Kaye, D., Jennings, G., and Esler, M.: Effect of sunlight and season on serotonin turnover in the brain, Lancet, 7, 360(9348):1840-2, 2002.

Matthews, G. and Deary, I.: Personality traits. Cambridge, UK, Cambridge University Press, 1998.

Michael, R. and Zumpe, D.: Sexual violence in the United States and the role of season, Am. J. Psychiat., 140, 883-886, 1983.

Murray, G., Hay, D., and Armstrong, S.: Personality factors in seasonal affective disorder: Is seasonality and aspect of neuroticism?, Pers. Indiv. Differ., 19, 613-617, 1995. 
Palinkas, L.: Mental and cognitive performance in the cold, Int. J. Cireumpolar Health, 60, 430-439, 2001.

Paspalanov, I., Shtetinski, D., and Eysenck, S.: Bulgarian adaptation of the Eysenck Personality Questionnaire, Psychology, 5, 279-292, 1984 (in Bulgarian).

Persinger, M.: Lag responses in mood reports to changes in the weather matrix, Int. J. Biometeor., 19, 108-114, 1975.

Rimskii, R. R. and Rimskii, S. A. (compilers): Almanac of psychological tests, Moscow, 1995 (in Russian).

Scott, J.: Impact of weather conditions on mood. The impact of weather conditions on mood variability in geographically relocated versus non-relocated individuals, Minnesota State University, Mankato, available at: http://www.mnsu.edu/urc/journal/ 2007/scott.pdf, 2007.

Shtetinski, D. and Paspalanov I.: Methodical guide for work with the Bulgarian form of the C. Spielberger's Anxiety Inventory (STAI - form Y), Sofia, 1989 (in Bulgarian).
Spielberger, C., Gorsuch, R., and Lushene, R.: The State-Trait Anxiety Inventory: Test manual, Palo Alto, CA, Consulting Psychologist Press, 1970.

Sulman, F.: Keine Angst mehr vor dem Föhn: die Wetterfühligkeit und ihre Behandlung, Umsch. Frankf. a/M, 80, 291-292, 294, 295, 1980.

Thomson, W.: A change of air, Charles Scribner, New York, 1979.

Tishkov, H.: Method of complex-climatic analysis - General climatology of D. Dimitrov, (3rd edn.), 1985 (in Bulgarian).

Trenkle, H.: Wetter und Mensch. Medizinische Welt, 33, 1285-128, 1982.

Tromp, S.: Studies on the origin and biological effects of the Chinook in western Canada, in: Biometeorological survey, vol. 1, part A: Human Biometeorology, edited by: Tromp, S. and Bouma, J., Heyden, London, 191-194, 1979.

Watson, D.: Mood and temperament, New York, Guilford Press, 2000. 